\title{
Sleep Apnea and Heart
}

\author{
Younghoon Kwon, $\mathrm{MD}^{1}$, Jeongok Logan, $\mathrm{PhD}, \mathrm{RN}^{2}$, Snigdha Pusalavidyasagar, $\mathrm{MD}^{3}$, \\ Takatoshi Kasai, MD, $\mathrm{PhD}^{4}$, Crystal SJ Cheong, $\mathrm{MBBS}^{5}$, Chi-Hang Lee, $\mathrm{MD}^{6}$ \\ 'Department of Medicine, University of Virginia, Charlottesville, VA, USA \\ 2University of Virginia School of Nursing, Charlottesville, VA, USA \\ ${ }^{3}$ Department of Medicine, University of Minnesota, Minneapolis, MN, USA \\ ${ }^{4}$ Department of Cardiovascular Medicine, Cardiovascular Respiratory Sleep Medicine, Juntendo University Graduate School of Medicine, Tokyo, Japan \\ ${ }^{5}$ Department of Otolaryngology-Head \& Neck Surgery, National University Hospital, Singapore \\ ${ }^{6}$ Department of Cardiology, National University Heart Centre, Singapore
}

Received: December 10, 2019

Accepted: December 20, 2019

\section{Correspondence}

Younghoon Kwon, MD

Cardiovascular Division,

Department of Medicine,

University of Virginia,

Charlottesville, VA 22908 USA

Tel +1-434-294-9591

Fax +1-434-982-1998

E-mail yk2j@virginia.edu

ORCID

Younghoon Kwon

https://orcid.org/0000-0002-8152-9170

Jeongok Logan

https://orcid.org/0000-0002-6599-6975

Snigdha Pusalavidyasagar

https://orcid.org/0000-0003-0498-6551

Takatoshi Kasai

https://orcid.org/0000-0001-5747-7668

Crystal SJ Cheong

https://orcid.org/0000-0002-7238-327X

Chi-Hang Lee

https://orcid.org/0000-0001-8777-2705
Scientific investigations in the past few decades have supported the important role of sleep in various domains of health. Sleep apnea is a highly prevalent yet underdiagnosed sleep disorder representing a valid cardiovascular risk factor, particularly for hypertension. While several studies have demonstrated the benefits of sleep apnea treatment on subclinical cardiovascular measures, there is a paucity of studies proving reduction of cardiovascular events and mortality. Sufficient and highquality sleep is also important in the maintenance of cardiovascular health. Future investigations should focus on improving identification of patients at greatest risk of adverse cardiovascular sequelae of sleep apnea and testing the therapeutic benefit of sleep apnea treatment in this vulnerable group.

Sleep Med Res 2019;10(2):67-74

Key Words Cardiovascular, Sleep, Sleep apnea.

\section{INTRODUCTION}

The importance of sleep in physical and mental well-being is generally acknowledged by both health professionals and the general public. Sleep apnea has been increasingly recognized as a potential cardiovascular risk factor. Initial physiological-based studies demonstrating acute effects on cardiovascular physiology during sleep have been followed by prospective epidemiological studies that supported the longitudinal association with cardiovascular disease (CVD). The aim of this review is to summarize major evidence accumulated and discuss future investigations under development in sleep and CVD. While the major focus will be on sleep apnea, other aspects of sleep will also be highlighted.

\section{Pathophysiology of Sleep Apnea's Impact on Cardiovascular System}

Obstructive sleep apnea (OSA) is defined by recurrent episodes of upper airway obstruction during sleep. In addition to upper airway anatomy, impairment of neuromodulatory control of the upper airway muscles during sleep plays an important role in the pathogenesis of OSA [1]. Repetitive forceful inspiration against a closed airway generates intrathoracic pressure swings, which in turn can increase left ventricular transmural pressure (Fig. 1) [2,3]. The resulting surges in sympathetic tone increases arterial stiffness and blood pressure (BP) (Fig. 2) [4]. Persistence of high sympathetic tone carried over to the hours spent awake may be an important mechanism of OSA-associated hypertension. Cessation of breathing leads to gas exchange abnormalities characterized by intermittent hypoxemia and hypercapnia-another important cause of increased sympathetic tone. Chronic intermittent hypoxemia is likely critical in ex- 


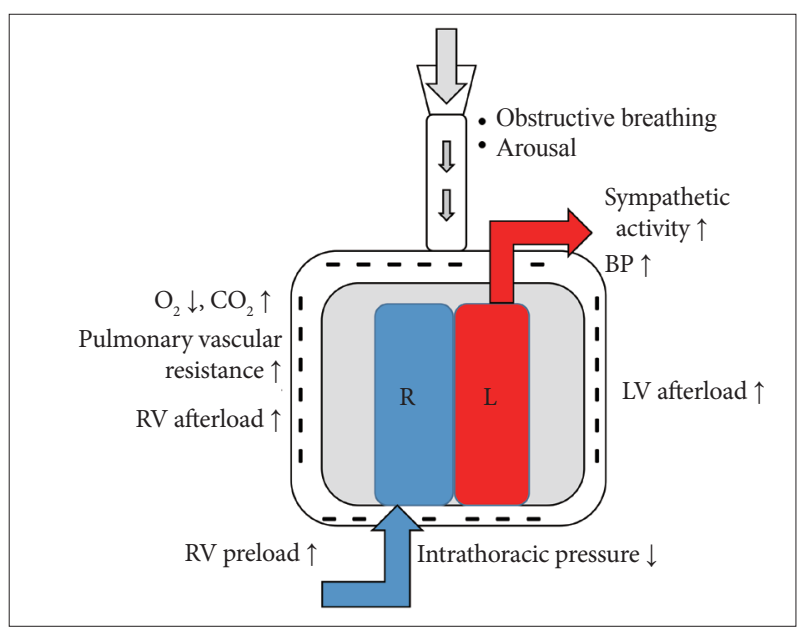

Fig. 1. Pathophysiology of obstructive sleep apnea. Forced inspiration against upper airway obstruction results in negative intrathoracic pressure (gray arrow denotes airflow), which leads to increase in right ventricular preload and left ventricular afterload. "-" in the space outside the lungs (gray color chamber) denotes negative intrathoracic pressure. Cessation of airflow results in intermittent hypoxemia and hypercapnia, which can increase pulmonary vascular resistance and right ventricular afterload. Increase in sympathetic activity with or without arousal accompanies varying degree of systemic BP increase. R: right heart, L: left heart, RV: right ventricle, LV: left ventricular, BP: blood pressure.

plaining many cardiovascular and metabolic consequences of OSA [5]. Moreover, the obstructive events frequently culminate in arousals, thereby disrupting sleep continuity and contributes to some of the symptoms of OSA such as non-restorative sleep and daytime sleepiness.

\section{Sleep Apnea and Hypertension}

The association between OSA and hypertension has been widely studied, and OSA has been established as an independent risk factor for hypertension (the Joint National Committee-7). Obstructive respiratory events leading to sympathetic surges are accompanied by varying degrees of acute elevation in BP. In fact, OSA is believed to be an important cause of non-dipping (lack of an appropriate decrease in BP that normally occurs in sleep). In addition to this nocturnal (more accurately "asleep") hypertension, OSA is also associated with daytime hypertension. A significant proportion of patients with resistant hypertension have concomitant OSA [6]. The Wisconsin cohort study, a landmark prospective cohort study, demonstrated a dose-response relationship between severity of OSA and risk of incident hypertension [7]. Subsequent prospective data from the Sleep Heart Health Study (SHHS) demonstrated a similar dose-response relationship between OSA and hypertension, though this was largely attenuated after adjusting for body mass index [8]. Indeed, hypertension is a component of the STOP-BANG Questionnaire, a commonly used OSA risk assessment tool [9]. Effective treatment of OSA with continuous positive airway pressure (CPAP) has been shown to improve long-term BP control based on 24-hour ambulatory BP monitoring [10]. While there is some

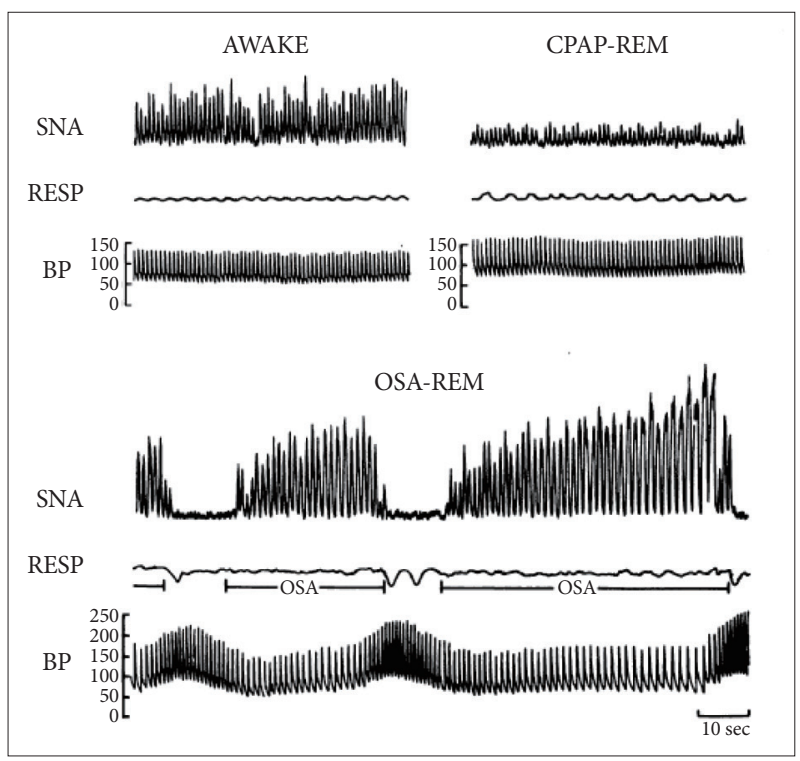

Fig. 2. Sympathetic nervous activity and BP during obstructive sleep apnea. SNA: sympathetic nervous activity, RESP: air flow, BP: blood pressure, CPAP: continuous positive airway pressure, REM: rapid eye movement. Adapted from Somers et al. J Clin Invest 1995;96:1897904 [4].

conflicting data, the literature overall shows that CPAP improves BP control, particularly among patients with resistant hypertension $[11,12]$. Considering the high prevalence of OSA and the adverse consequences of both daytime and nocturnal hypertension on cardiovascular outcomes, identification, and the treatment of OSA among patients with hypertension has important public health implications.

\section{Sleep Apnea and Atrial Fibrillation}

Atrial fibrillation (AF) is one of the most prevalent chronic arrhythmias, affecting millions in the United States. The rise in its prevalence is partly attributed to a rapidly aging population [13], but ongoing efforts are being made to identify novel and potentially modifiable risk factors for AF. OSA is highly common in patients with AF. Moreover, the relative risk of having nocturnal AF was found to be markedly higher in people with severe sleep apnea in the SHHS [14]. However, association between the prevalence of sleep apnea and AF (beyond nocturnal AF) in unselected populations from the community remains uncertain. In the multi-ethnic study of atherosclerosis, the prevalence of AF increased according to the severity of OSA. Moreover, there is evidence that OSA plays a role in the recurrence of AF following catheter-based AF ablation, while treatment of OSA with CPAP appears to reduce the risk $[15,16]$. However, such findings have not been replicated in other observational studies, reflecting some degree of uncertainty as to whether OSA truly contributes to post-ablation AF recurrence $[17,18]$. While awaiting results from several ongoing randomized controlled trials (RCTs) on this issue, screening and treatment of OSA in the presence of sleep-related symptoms seems reasonable [19]. Future studies 
are warranted to identify high-risk groups for incident or recurrent $\mathrm{AF}$ among patients with OSA [20]. For example, it is possible that patients with OSA with either electrographic or structural left atrial pathology may be at much higher risk for developing AF [21-23]. Such information can help to arrive at treatment decisions in patients without obvious symptoms. Additionally, other elements of sleep may play a possible role in AF. Lack of deep sleep was found to be more common in patients with AF independent of OSA [24,25]. A recent observational study showed that lack of rapid eye movement sleep is associated with an increased risk of incident AF [26]. Both subjectively reported sleep difficulty and objectively assessed short sleep duration have been linked to AF [26,27]. These findings highlight the complex interplay between sleep in its entirety and AF [20].

\section{Sleep Apnea and Sudden Cardiac Death}

Out-of-hospital sudden cardiac death (SCD) is a major cause of cardiac mortality. A limited but emerging body of research has further elaborated on the link between sleep apnea and SCD. There is a paucity of epidemiological data examining the association between OSA and SCD due to relative rarity of the event in existing sleep cohort studies. One clinic-based cohort study showed that the lowest nocturnal oxygen saturation was independently, albeit modestly, predictive of SCD in an average 5year follow-up period [28]. However, it is plausible that the SCD could have resulted from other underlying cardiopulmonary conditions or morbid obesity, which are associated with both oxygen saturation and SCD [29]. Despite these limitations, this study represents the first of its kind to suggest OSA as a possible independent risk factor for SCD. Circadian timing of SCD may be shifted in patients OSA [30,31]. The relative risk for SCD was significantly higher between midnight and 6 a.m. in patients with OSA compared to the general population [30]. One mechanism that would explain the link is the influence of OSA on ventricular depolarization and repolarization. Patients with OSA more commonly exhibit high risk electrocardiographic markers such as prolonged QT, T peak to T end (TpTe) interval and high QRS-T angle, all of which confer high risk for malignant arrhythmias [32-34]. Although the role of OSA in SCD needs further elucidation, we speculate that OSA possibly increases the risk of SCD via increasing risks for other CVD such as coronary heart disease. Appropriate implantable cardioverter-defibrillator therapy is more common in heart failure $(\mathrm{HF})$ patients with sleep apnea [both OSA and central sleep apnea (CSA)], which suggests the risk of SCD in these patients [35].

\section{Sleep Apnea and Stroke}

Sleep apnea is common in patients with stroke or transient ischemic attack (TIA) [36-39]. On the other hand, OSA appears to increase the risk of ischemic stroke. In the landmark study by Yaggi et al. [40], OSA was associated with a two-fold increased risk of stroke or death. Furthermore, there was a dose-response relationship between the severity of OSA and the risk of ischemic stroke. In the SHHS, men, but not women, in the highest quartile apnea-hypopnea index had approximately three times higher risk of ischemic stroke compared to those in the lowest quartile [41]. Aggravation of cerebrovascular abnormalities, hypertension and AF are speculated to be some of the mechanisms. In the sleep apnea cardiovascular endpoints (SAVE) trial, there was no difference in the incidence of stroke, one of the primary outcomes, between those who were randomized to CPAP vs. no CPAP [42]. In terms of CPAP effect on the outcomes among patients with stroke, a RCT is underway to test whether treatment of OSA with CPAP immediately after stroke or TIA would improve outcomes [Sleep for Stroke Management and Recovery Trial (Sleep SMART; https://clinicaltrials.gov/ ct2/show/NCT03812653)].

\section{Sleep Apnea and Coronary Artery Disease}

OSA is common in patients with coronary artery disease (CAD). About one third of patients with stable CAD were noted to have OSA $[43,44]$. In patients with acute myocardial infarction (MI), the prevalence of OSA is even greater, with some reports citing figures as high as 66\% [45]. However, severity of OSA may resolve from the acute to recovery phase following acute MI. Of the patients newly diagnosed with OSA at index admission (46\%), resolution of OSA was seen in approximately half six months later [46]. Increased platelet activation and aggregation, along with endothelial dysfunction due to inflammation and oxidative stress, predispose to atherosclerotic plaque formation in OSA [47]. OSA is also associated with a higher burden and progression of coronary artery calcification, which is a potent predictor of acute MI and CVD [48,49]. More importantly, two major sleep cohort studies showed increased risk of future CAD in patients with OSA [50,51]. OSA was also found to be independently associated with a larger coronary atheroma volume, but not with necrotic core volume, based on an intravascular ultrasound with virtual histology technology in patients undergoing coronary angiogram [52]. OSA also leads to more adverse outcomes in patients undergoing percutaneous coronary intervention [53]. In the post-hoc analysis of patients with concomitant diabetes, OSA increased the risk of adverse cardiovascular events by two-fold [54]. In particular, the 3-year estimated cumulative incidence of cardiovascular mortality for patients with both OSA and diabetes over a median follow-up period of 1.9 years was $7.4 \%$, compared to $1.4 \%$ in those with diabetes but without OSA ( $p=0.002)$ [54]. In patients undergoing non-urgent coronary artery bypass surgery, OSA was independently associated with a nearly 5 times higher likelihood of unscheduled re-admissions due to cardiovascular events at 6month follow-up [55]. The ultimate question is whether OSA treatment would effectively lower this increased risk of cardiovascular events. A small pilot study using hybrid positron emission tomography/magnetic resonance imaging technology with 
${ }^{18} \mathrm{~F}$-FDG tracer measured vascular inflammation in patients with OSA. The study demonstrated a decrease in carotid plaque activity in patients with good adherence to optimum CPAP therapy for a minimum period of 3 months. Quantitative analysis showed reduction of carotid and aortic plaque inflammation, comparable to outcomes achieved with statin therapy [56]. However, in the SAVE trial, CPAP therapy did not reduce cardiovascular events including acute MI [42]. In a recent RCT, OSA screening and treatment via a multidisciplinary approach (vs. no OSA screening and treatment) in patients with acute coronary syndrome did not lead to reduction in the levels of cardiovascular biomarkers such as $\mathrm{N}$-terminal pro-brain natriuretic peptide, suppression of tumorigenicity 2 and high-sensitivity C-reactive protein [57]. It therefore remains uncertain whether OSA treatment improves the outcomes following acute MI.

\section{Sleep Apnea and Heart Failure}

Several epidemiological studies have suggested that sleep apnea is associated with an increased risk of incident HF [50,51, 58]. In patients with HF, sleep apnea is highly prevalent $[59,60]$. A unique feature of sleep apnea in patients with HF is the high prevalence of CSA (15-40\%) in addition to OSA (12-53\%) [6064]. CSA typically accompanies Cheyne-Stokes breathing, a form of periodic breathing characterized by a crescendo-decrescendo pattern of hyperpnea, followed by central apnea or hypopnea. The mechanism involves instability of the respiratory control system in association with pulmonary congestion, increased chemosensitivity, and delayed circulation time [65-67]. Both OSA and CSA are associated with increased mortality in patients with HF $[68,69]$. Although CSA is more likely a consequence rather than a cause of HF, CSA initiates a vicious cycle that could cause further deterioration and increased mortality in HF patients $[65,66,70]$. Several short-term RCTs showed beneficial effects of OSA treatment with CPAP on cardiac function, such as increase in left ventricular ejection fraction (LVEF) in patients with HF [68]. Although no RCTs showed the effects of CPAP on mortality in OSA patients with HF, observational studies suggested that OSA treatment with CPAP was associated with decreased risk of mortality [68,69,71]. In patients with CSA, optimization of HF treatment should be prioritized as CSA improves with improvement in HF $[65,66]$. Whether suppression of CSA by itself improves the clinical outcomes is unclear. The Canadian Continuous Positive Airway Pressure for Treatment of Central Sleep Apnea in Heart Failure (CANPAP) trial showed that CPAP alleviated CSA, and improved LVEF, but failed to show mortality benefit. This could possibly be due to insufficient suppression of CSA, observed in about half of the participants in the CPAP group [72,73]. Therefore, routine use of CPAP is not supported for patients with HF and CSA, but may be used if CSA can be sufficiently suppressed by CPAP. Although CPAP may suppress CSA (possibly through cardiac unloading), CPAP is typically not very effective in treating CSA [74]. Adaptive ser- vo-ventilation (ASV) is an advanced mode of bi-level positive airway pressure developed for the treatment of CSA $[75,76]$. Short-term RCTs showed beneficial effects on cardiac function in those with CSA treated by ASV [65]. However, in the Treatment of Predominant Central Sleep Apnea by ASV in Patients With Heart Failure (SERVE-HF) trial, ASV failed to show mortality benefit [77]. In addition, all-cause and cardiovascular mortalities and secondary endpoints were significantly worse in patients treated with ASV compared with the control group. Although specific reasons for this remain unknown, nonadherence to the study protocol (29\% of patients in the ASV group either discontinued use of ASV or never used it, and $17 \%$ of patients in the control group crossed over to positive airway pressure therapy) may play some role. One ongoing RCT using ASV in patients with $\mathrm{HF}$ and CSA, a multi-centre, randomized study to assess the Effects of Adaptive Servo Ventilation on Survival and Frequency of Cardiovascular Hospital Admissions in Patients with Heart Failure and Sleep Apnea (ADVENT-HF), may shed more light on the impact of treatment of CSA with ASV [78]. Supplemental oxygen during sleep has been shown to alleviate CSA and increase the exercise capacity $[79,80]$. The Impact of Low Flow Nocturnal Oxygen Therapy on Hospital Admissions and Mortality in Patients With Heart Failure and Central Sleep Apnea (LOFT-HF) RCT trial is underway to assess the effectiveness of supplemental oxygen in clinical outcomes (https://clinicaltrials.gov/ct2/show/NCT03254212). Phrenic nerve stimulation is a novel option that has been shown to be effective in suppressing CSA and improving sleep, quality of life and LVEF [81-85]. RCTs are warranted to confirm clinical efficacy of phrenic nerve stimulation on HF.

\section{Other Sleep Aspects and Cardiovascular Disease}

Sleep is one of the foremost critical behavioral factors for overall health, as well as physiological processes, emotion regulation, cognitive performance, and quality of life [86]. There is a growing body of evidence supporting both abnormal sleep duration and poor sleep quality as important risk factors for CVD. Both self-reported or objectively measured short and long sleep duration have been found to be associated with subclinical and clinical CVD [27,87-95]. A meta-analysis of prospective studies including 474686 participants with 6.9-25 years of follow-up showed a U-shaped association between sleep duration and CVD, reporting that individuals with either shorter or longer sleep than 7-8 hours per night are at increased risk of CVD [96]. While this U-shaped has generally been advocated, the relation is more complex. For example, objectively measured sleep duration had a positive linear relationship with arterial stiffness in the community-dwelling elderly population [97]. Furthermore, a meta-analysis on over 3 million participants demonstrated a J-shaped relationship between sleep duration and increased risk for mortality and incident CVD [98]. Unlike subjective sleep quality, definition of objective sleep quality is more complex [99]. 
Increased sleep efficiency, reduced wake after sleep onset time and sufficient time spent in deep sleep (such as slow wave sleep and rapid eye movement sleep) are often used as indicators of good sleep quality [100]. Similar to sleep duration, both selfreported and objective sleep quality have been linked to subclinical and clinical CVD [24,25,101-106]. Therefore, both sleep duration and sleep quality are vital as these present as several phenotypes with varying degrees of health consequences. For example, one large cohort study showed that over 10-15 years of follow-up, short sleepers had a 15\% higher risk of CVD and a $23 \%$ higher risk of CAD compared with normal sleepers. However, short sleepers with poor sleep quality had a $63 \%$ higher risk of CVD and a 79\% higher risk of CAD compared with normal sleepers with good sleep quality [107]. A recent large nationwide cohort study from Taiwan reported that having a history of a non-sleep apnea disorder based on international diagnostic codes was associated with an increased risk of HF [108]. Another nationwide cohort study reported increased risk of ischemic stroke with insomnia [109]. Many existing studies looking at the interface of sleep and CVD have generally focused on a single domain of sleep (e.g., sleep apnea alone). The multidimensional nature of sleep has been overlooked. In fact, many studies examining subjective sleep duration and quality in relation to CVD lacked objective sleep studies, and studies examining sleep apnea lacked subjective sleep report, all of which are equally important. As a result, it is often difficult to fully appreciate the independent associations of individual components from these studies. Furthermore, psychological factors are known to have a major impact on both sleep and CVD $[110,111]$. Given behavioral mediation of the relationship between psychological factors and health outcomes, it is plausible that impaired sleep may be a critical mediator of the relationship between stress and CVD. Further studies deciphering this complex interaction between stress, sleep, and cardiovascular health are warranted.

\section{Future Directions}

A growing body of evidence has been pointing to adverse effects of sleep apnea on cardiovascular health. In symptomatic patients with sleep apnea, treatment of sleep apnea improves sleep quality and quality of life regardless of their cardiovascular risks or burden [112]. Considering the high burden of sleep apnea in patients with cardiovascular comorbidities, timely screening and treatment are important. However, there is a remaining question about whether treatment of sleep apnea improves cardiovascular-related clinical outcomes beyond the quality of life. Several ongoing RCTs may help narrow this gap. Searching for sleep study metrics and other physiological markers that would better characterize cardiovascular impact of sleep apnea and response to therapy beyond conventional respiratory-centric metrics would be highly valuable. Other areas that lack high quality evidence on the impact of sleep apnea and its treatment include pulmonary hypertension and peripheral vas- cular disease. In the context of primary prevention, more investigations are needed to better identify high-risk patients who may benefit from sleep apnea treatment. The common treatment modality of choice for OSA is CPAP, but it is not well accepted and tolerated by most patients. Development of cost-effective and more convenient therapies for sleep apnea is critically needed. Furthermore, the role of other aspects of sleep beyond sleep apnea in mediating the outcomes in patients with CVD warrant further investigation.

\section{CONCLUSION}

In conclusion, sleep apnea is common in patients with CVD and is an important cardiovascular risk factor. More studies are needed to confirm the benefit of sleep apnea treatment in primary and secondary prevention of CVD.

\section{Acknowledgments}

This work was partially supported by NIH R21HL140432 (YK).

\section{Conflicts of Interest}

The authors have no financial conflicts of interest.

\section{Authors' Contribution}

Conceptualization: Kwon Y. Funding acquisition: Kwon Y. Writing-original draft: Kwon Y, Logan J, Kasai T, Cheong CSJ, Lee CH. Writing-review \& editing: Kwon Y, Logan J, Pusalavidyasagar S, Kasai T, Cheong CSJ, Lee $\mathrm{CH}$.

\section{REFERENCES}

1. Dempsey JA, Veasey SC, Morgan BJ, O’Donnell CP. Pathophysiology of sleep apnea. Physiol Rev 2010;90:47-112.

2. Kwon Y, Debaty G, Puertas L, Metzger A, Rees J, McKnite S, et al. Effect of regulating airway pressure on intrathoracic pressure and vital organ perfusion pressure during cardiopulmonary resuscitation: a non-randomized interventional cross-over study. Scand J Trauma Resusc Emerg Med 2015;23:83.

3. Tolle FA, Judy WV, Yu PL, Markand ON. Reduced stroke volume related to pleural pressure in obstructive sleep apnea. J Appl Physiol Respir Environ Exerc Physiol 1983;55:1718-24.

4. Somers VK, Dyken ME, Clary MP, Abboud FM. Sympathetic neural mechanisms in obstructive sleep apnea. J Clin Invest 1995;96:1897904.

5. Sforza E, Roche F. Chronic intermittent hypoxia and obstructive sleep apnea: an experimental and clinical approach. Hypoxia (Auckl) 2016;4: 99-108.

6. Walia HK, Li H, Rueschman M, Bhatt DL, Patel SR, Quan SF, et al. Association of severe obstructive sleep apnea and elevated blood pressure despite antihypertensive medication use. J Clin Sleep Med 2014; 10:835-43.

7. Peppard PE, Young T, Palta M, Skatrud J. Prospective study of the association between sleep-disordered breathing and hypertension. $N$ Engl J Med 2000;342:1378-84.

8. O'Connor GT, Caffo B, Newman AB, Quan SF, Rapoport DM, Redline $\mathrm{S}$, et al. Prospective study of sleep-disordered breathing and hypertension: the Sleep Heart Health Study. Am J Respir Crit Care Med 2009;179:1159-64.

9. Chung F, Yegneswaran B, Liao P, Chung SA, Vairavanathan S, Islam S, 
et al. STOP questionnaire: a tool to screen patients for obstructive sleep apnea. Anesthesiology 2008;108:812-21.

10. Deleanu OC, Oprea CI, Malaut AE, Zaharie AM, Micheu MM, Patrascu N, et al. Long-term effects of CPAP on blood pressure in nonresistant hypertensive patients with obstructive sleep apnea: a 30 month prospective study. Eur Respir J 2016;48:PA2082.

11. Martínez-García MA, Capote F, Campos-Rodríguez F, Lloberes P, Díaz de Atauri MJ, Somoza M, et al. Effect of CPAP on blood pressure in patients with obstructive sleep apnea and resistant hypertension: the HIPARCO randomized clinical trial. JAMA 2013;310:2407-15.

12. Javaheri S, Gottlieb DJ, Quan SF. Effects of continuous positive airway pressure on blood pressure in obstructive sleep apnea patients: The Apnea Positive Pressure Long-term Efficacy Study (APPLES). J Sleep Res 2019:e12943.

13. Benjamin EJ, Levy D, Vaziri SM, D’Agostino RB, Belanger AJ, Wolf PA. Independent risk factors for atrial fibrillation in a population-based cohort. The Framingham Heart Study. JAMA 1994;271:840-4.

14. Mehra R, Benjamin EJ, Shahar E, Gottlieb DJ, Nawabit R, Kirchner $\mathrm{HL}$, et al. Association of nocturnal arrhythmias with sleep-disordered breathing: The Sleep Heart Health Study. Am J Respir Crit Care Med 2006;173:910-6.

15. Ng CY, Liu T, Shehata M, Stevens S, Chugh SS, Wang X. Meta-analysis of obstructive sleep apnea as predictor of atrial fibrillation recurrence after catheter ablation. Am J Cardiol 2011;108:47-51.

16. Qureshi WT, Nasir UB, Alqalyoobi S, O’Neal WT, Mawri S, Sabbagh $\mathrm{S}$, et al. Meta-analysis of continuous positive airway pressure as a therapy of atrial fibrillation in obstructive sleep apnea. Am J Cardiol 2015; 116:1767-73.

17. Srivali N, Chahal AC, Mansukhani MP, Mandrekar J, Somers VK, Caples SM. The effect of positive airway pressure treatment of obstructive and central sleep apnea on the recurrence of atrial fibrillation/ flutter postintervention. J Clin Sleep Med 2019;15:1459-68.

18. Lee CJ, Kim TH, Park S, Pak HN. Obstructive sleep apnea is closely related to cardiovascular risk factors, but not to clinical recurrence of atrial fibrillation after catheter ablation: an analysis of atrial fibrillation patients. Pulse (Basel) 2018;6:103-11.

19. Traaen GM, Aakerøy L, Hunt TE, Øverland B, Lyseggen E, Aukrust P, et al. Treatment of sleep apnea in patients with paroxysmal atrial fibrillation: design and rationale of a randomized controlled trial. Scand Cardiovasc J 2018;52:372-7.

20. Kwon Y, Koene RJ, Johnson AR, Lin GM, Ferguson JD. Sleep, sleep apnea and atrial fibrillation: questions and answers. Sleep Med Rev 2018; 39:134-42.

21. Corotto PS, Kang H, Massaro B, Harding WC, Shah NR, Gadi S, et al. Obstructive sleep apnea and electrocardiographic P-wave morphology. Ann Noninvasive Electrocardiol 2019;24:e12639.

22. Kwon Y, Misialek JR, Duprez D, Alonso A, Jacobs DR Jr, Heckbert SR, et al. Association between sleep disordered breathing and electrocardiographic markers of atrial abnormalities: the MESA study. Europace 2017;19:1759-66.

23. Psaty BM, Manolio TA, Kuller LH, Kronmal RA, Cushman M, Fried LP, et al. Incidence of and risk factors for atrial fibrillation in older adults. Circulation 1997;96:2455-61.

24. Kwon Y, Gadi S, Shah NR, Stout C, Blackwell JN, Cho Y, et al. Atrial fibrillation and objective sleep quality by slow wave sleep. J Atr Fibrillation 2018;11:2031.

25. Kwon Y, Gharib SA, Biggs ML, Jacobs DR Jr, Alonso A, Duprez D, et al. Association of sleep characteristics with atrial fibrillation: the MultiEthnic Study of Atherosclerosis. Thorax 2015;70:873-9.

26. Christensen MA, Dixit S, Dewland TA, Whitman IR, Nah G, Vittinghoff E, et al. Sleep characteristics that predict atrial fibrillation. Heart Rhythm 2018;15:1289-95.

27. Genuardi MV, Ogilvie RP, Saand AR, DeSensi RS, Saul MI, Magnani JW, et al. Association of short sleep duration and atrial fibrillation. Chest 2019;156:544-52.
28. Gami AS, Olson EJ, Shen WK, Wright RS, Ballman KV, Hodge DO, et al. Obstructive sleep apnea and the risk of sudden cardiac death: a longitudinal study of 10,701 adults. J Am Coll Cardiol 2013;62:610-6.

29. Adabag S, Huxley RR, Lopez FL, Chen LY, Sotoodehnia N, Siscovick $\mathrm{D}$, et al. Obesity related risk of sudden cardiac death in the atherosclerosis risk in communities study. Heart 2015;101:215-21.

30. Gami AS, Howard DE, Olson EJ, Somers VK. Day-night pattern of sudden death in obstructive sleep apnea. N Engl J Med 2005;352:120614.

31. Martins EF, Martinez D, da Silva FABS, Sezerá L, da Rosa de Camargo R, Fiori CZ, et al. Disrupted day-night pattern of cardiovascular death in obstructive sleep apnea. Sleep Med 2017;38:144-50.

32. Kwon Y, Misialek JR, Duprez D, Jacobs DR Jr, Alonso A, Heckbert SR, et al. Sleep-disordered breathing and electrocardiographic QRS-T angle: the MESA study. Ann Noninvasive Electrocardiol 2018;23:e12579.

33. Rossi VA, Stoewhas AC, Camen G, Steffel J, Bloch KE, Stradling JR, et al. The effects of continuous positive airway pressure therapy withdrawal on cardiac repolarization: data from a randomized controlled trial. Eur Heart J 2012;33:2206-12.

34. Shamsuzzaman A, Amin RS, van der Walt C, Davison DE, Okcay A, Pressman GS, et al. Daytime cardiac repolarization in patients with obstructive sleep apnea. Sleep Breath 2015;19:1135-40.

35. Kwon Y, Koene RJ, Kwon O, Kealhofer JV, Adabag S, Duval S. Effect of sleep-disordered breathing on appropriate implantable cardioverter-defibrillator therapy in patients with heart failure: a systematic review and meta-analysis. Circ Arrhythm Electrophysiol 2017;10:e004609.

36. Good DC, Henkle JQ, Gelber D, Welsh J, Verhulst S. Sleep-disordered breathing and poor functional outcome after stroke. Stroke 1996;27: 252-9.

37. Martínez-García MA, Campos-Rodríguez F, Soler-Cataluña JJ, Catalán-Serra P, Román-Sánchez P, Montserrat JM. Increased incidence of nonfatal cardiovascular events in stroke patients with sleep apnoea: effect of CPAP treatment. Eur Respir J 2012;39:906-12.

38. Johnson KG, Johnson DC. Frequency of sleep apnea in stroke and TIA patients: a meta-analysis. J Clin Sleep Med 2010;6:131-7.

39. Brown DL, Shafie-Khorassani F, Kim S, Chervin RD, Case E, Morgenstern LB, et al. Sleep-disordered breathing is associated with recurrent ischemic stroke. Stroke 2019;50:571-6.

40. Yaggi HK, Concato J, Kernan WN, Lichtman JH, Brass LM, Mohsenin V. Obstructive sleep apnea as a risk factor for stroke and death. $N$ Engl J Med 2005;353:2034-41.

41. Redline S, Yenokyan G, Gottlieb DJ, Shahar E, O'Connor GT, Resnick $\mathrm{HE}$, et al. Obstructive sleep apnea-hypopnea and incident stroke: the sleep heart health study. Am J Respir Crit Care Med 2010;182:269-77.

42. McEvoy RD, Antic NA, Heeley E, Luo Y, Ou Q, Zhang X, et al. CPAP for prevention of cardiovascular events in obstructive sleep apnea. $N$ Engl J Med 2016;375:919-31.

43. Mooe T, Rabben T, Wiklund U, Franklin KA, Eriksson P. Sleep-disordered breathing in women: occurrence and association with coronary artery disease. Am J Med 1996;101:251-6.

44. Mooe T, Rabben T, Wiklund U, Franklin KA, Eriksson P. Sleep-disordered breathing in men with coronary artery disease. Chest 1996;109: 659-63.

45. Lee CH, Khoo SM, Tai BC, Chong EY, Lau C, Than Y, et al. Obstructive sleep apnea in patients admitted for acute myocardial infarction. Prevalence, predictors, and effect on microvascular perfusion. Chest 2009; 135:1488-95.

46. Tan LL, Ting J, Balakrishnan I, Seneviratna A, Gong L, Chan MY, et al. Sleep apnea evolution and left ventricular recovery after percutaneous coronary intervention for myocardial infarction. J Clin Sleep Med 2018;14:1773-81.

47. Kohler M, Stradling JR. Mechanisms of vascular damage in obstructive sleep apnea. Nat Rev Cardiol 2010;7:677-85.

48. Kwon Y, Duprez DA, Jacobs DR, Nagayoshi M, McClelland RL, Shahar E, et al. Obstructive sleep apnea and progression of coronary ar- 
tery calcium: the multi-ethnic study of atherosclerosis study. J Am Heart Assoc 2014;3:e01241.

49. Sorajja D, Gami AS, Somers VK, Behrenbeck TR, Garcia-Touchard A, Lopez-Jimenez F. Independent association between obstructive sleep apnea and subclinical coronary artery disease. Chest 2008;133:927-33.

50. Gottlieb DJ, Yenokyan G, Newman AB, O'Connor GT, Punjabi NM, Quan SF, et al. Prospective study of obstructive sleep apnea and incident coronary heart disease and heart failure: the sleep heart health study. Circulation 2010;122:352-60.

51. Hla KM, Young T, Hagen EW, Stein JH, Finn LA, Nieto FJ, et al. Coronary heart disease incidence in sleep disordered breathing: the Wisconsin Sleep Cohort Study. Sleep 2015;38:677-84.

52. Tan A, Hau W, Ho HH, Ghaem Maralani H, Loo G, Khoo SM, et al. OSA and coronary plaque characteristics. Chest 2014;145:322-30.

53. Lee CH, Sethi R, Li R, Ho HH, Hein T, Jim MH, et al. Obstructive sleep apnea and cardiovascular events after percutaneous coronary intervention. Circulation 2016;133:2008-17.

54. Koo CY, Drager LF, Sethi R, Ho HH, Hein T, Jim MH, et al. Obstructive sleep apnea and diabetes independently add to cardiovascular risk after coronary revascularization. Diabetes Care 2018;41:e12-4.

55. Zhao LP, Kofidis T, Chan SP, Ong TH, Yeo TC, Tan HC, et al. Sleep apnoea and unscheduled re-admission in patients undergoing coronary artery bypass surgery. Atherosclerosis 2015;242:128-34.

56. Kundel V, Trivieri MG, Karakatsanis NA, Robson PM, Mani V, Kizer $J R$, et al. Assessment of atherosclerotic plaque activity in patients with sleep apnea using hybrid positron emission tomography/magnetic resonance imaging (PET/MRI): a feasibility study. Sleep Breath 2018;22: 1125-35.

57. Koo CY, Chua AP, Kristanto W, Koh EH, Tan ES, Abd Rahman S, et al. Screening and treatment of obstructive sleep apnea in acute coronary syndrome. A randomized clinical trial. Int J Cardiol 2020;299:20-5.

58. Javaheri S, Blackwell T, Ancoli-Israel S, Ensrud KE, Stone KL, Redline S. Sleep-disordered breathing and incident heart failure in older men. Am J Respir Crit Care Med 2016;193:561-8.

59. Javaheri S, Parker TJ, Liming JD, Corbett WS, Nishiyama H, Wexler L, et al. Sleep apnea in 81 ambulatory male patients with stable heart failure. Types and their prevalences, consequences, and presentations. Circulation 1998;97:2154-9.

60. Oldenburg O, Lamp B, Faber L, Teschler H, Horstkotte D, Töpfer V. Sleep-disordered breathing in patients with symptomatic heart failure: a contemporary study of prevalence in and characteristics of $700 \mathrm{pa}-$ tients. Eur J Heart Fail 2007;9:251-7.

61. Ferrier K, Campbell A, Yee B, Richards M, O’Meeghan T, Weatherall $\mathrm{M}$, et al. Sleep-disordered breathing occurs frequently in stable outpatients with congestive heart failure. Chest 2005;128:2116-22.

62. Javaheri S. Sleep disorders in systolic heart failure: a prospective study of 100 male patients. The final report. Int J Cardiol 2006;106:21-8.

63. Vazir A, Hastings PC, Dayer M, McIntyre HF, Henein MY, Poole-Wilson PA, et al. A high prevalence of sleep disordered breathing in men with mild symptomatic chronic heart failure due to left ventricular systolic dysfunction. Eur J Heart Fail 2007;9:243-50.

64. Yumino D, Wang H, Floras JS, Newton GE, Mak S, Ruttanaumpawan $\mathrm{P}$, et al. Prevalence and physiological predictors of sleep apnea in patients with heart failure and systolic dysfunction. J Card Fail 2009;15: 279-85.

65. Kasai T. Sleep apnea and heart failure. J Cardiol 2012;60:78-85.

66. Kasai T, Floras JS, Bradley TD. Sleep apnea and cardiovascular disease: a bidirectional relationship. Circulation 2012;126:1495-510.

67. Kwon Y, Khan T, Pritzker M, Iber C. Circulation time measurement from sleep studies in patients with obstructive sleep apnea. J Clin Sleep Med 2014;10:759-65, 765A

68. Kasai T, Bradley TD. Obstructive sleep apnea and heart failure: pathophysiologic and therapeutic implications. J Am Coll Cardiol 2011;57: 119-27.

69. Wang H, Parker JD, Newton GE, Floras JS, Mak S, Chiu KL, et al. In- fluence of obstructive sleep apnea on mortality in patients with heart failure. J Am Coll Cardiol 2007;49:1625-31.

70. Javaheri S, Shukla R, Zeigler H, Wexler L. Central sleep apnea, right ventricular dysfunction, and low diastolic blood pressure are predictors of mortality in systolic heart failure. J Am Coll Cardiol 2007;49: 2028-34.

71. Kasai T, Narui K, Dohi T, Yanagisawa N, Ishiwata S, Ohno M, et al. Prognosis of patients with heart failure and obstructive sleep apnea treated with continuous positive airway pressure. Chest 2008;133:690-6.

72. Arzt M, Floras JS, Logan AG, Kimoff RJ, Series F, Morrison D, et al. Suppression of central sleep apnea by continuous positive airway pressure and transplant-free survival in heart failure: a post hoc analysis of the Canadian Continuous Positive Airway Pressure for Patients with Central Sleep Apnea and Heart Failure Trial (CANPAP). Circulation 2007;115:3173-80.

73. Bradley TD, Logan AG, Kimoff RJ, Sériès F, Morrison D, Ferguson K, et al. Continuous Positive Airway Pressure for Central Sleep Apnea and Heart Failure. N Engl J Med 2005;353:2025-33.

74. Kato T, Suda S, Kasai T. Positive airway pressure therapy for heart failure. World J Cardiol 2014;6:1175-91.

75. Teschler H, Döhring J, Wang YM, Berthon-Jones M. Adaptive pressure support servo-ventilation: a novel treatment for Cheyne-Stokes respiration in heart failure. Am J Respir Crit Care Med 2001;164:614-9.

76. Kasai T, Narui K, Dohi T, Takaya H, Yanagisawa N, Dungan G, et al. First experience of using new adaptive servo-ventilation device for Cheyne-Stokes respiration with central sleep apnea among Japanese patients with congestive heart failure: report of 4 clinical cases. Circ J 2006;70:1148-54.

77. Cowie MR, Woehrle H, Wegscheider K, Angermann C, d'Ortho MP, Erdmann E, et al. Adaptive servo-ventilation for central sleep apnea in systolic heart failure. N Engl J Med 2015;373:1095-105.

78. Lyons OD, Floras JS, Logan AG, Beanlands R, Cantolla JD, Fitzpatrick $\mathrm{M}$, et al. Design of the effect of adaptive servo-ventilation on survival and cardiovascular hospital admissions in patients with heart failure and sleep apnoea: the ADVENT-HF trial. Eur J Heart Fail 2017;19:57987.

79. Shigemitsu M, Nishio K, Kusuyama T, Itoh S, Konno N, Katagiri T. Nocturnal oxygen therapy prevents progress of congestive heart failure with central sleep apnea. Int J Cardiol 2007;115:354-60.

80. Sasayama S, Izumi T, Seino Y, Ueshima K, Asanoi H. Effects of nocturnal oxygen therapy on outcome measures in patients with chronic heart failure and cheyne-stokes respiration. Circ J 2006;70:1-7.

81. Abraham WT, Jagielski D, Oldenburg O, Augostini R, Krueger S, Kolodziej A, et al. Phrenic nerve stimulation for the treatment of central sleep apnea. JACC Heart Fail 2015;3:360-9.

82. Ponikowski P, Javaheri S, Michalkiewicz D, Bart BA, Czarnecka D, Jastrzebski $M$, et al. Transvenous phrenic nerve stimulation for the treatment of central sleep apnoea in heart failure. Eur Heart J 2012;33: 889-94.

83. Jagielski D, Ponikowski P, Augostini R, Kolodziej A, Khayat R, Abraham WT. Transvenous stimulation of the phrenic nerve for the treatment of central sleep apnoea: 12 months' experience with the remedēe System. Eur J Heart Fail 2016;18:1386-93.

84. Costanzo MR, Ponikowski P, Coats A, Javaheri S, Augostini R, Goldberg LR, et al. Phrenic nerve stimulation to treat patients with central sleep apnoea and heart failure. Eur J Heart Fail 2018;20:1746-54.

85. Fudim M, Spector AR, Costanzo MR, Pokorney SD, Mentz RJ, Jagielski D, et al. Phrenic nerve stimulation for the treatment of central sleep apnea: a pooled cohort analysis. J Clin Sleep Med 2019;15:1747-55.

86. Hirshkowitz M, Whiton K, Albert SM, Alessi C, Bruni O, DonCarlos L, et al. National Sleep Foundation's updated sleep duration recommendations: final report. Sleep Health 2015;1:233-43.

87. Song Q, Liu X, Hu W, Zhou W, Liu A, Wang X, et al. Long sleep duration is an independent risk factor for incident atrial fibrillation in a Chinese population: a prospective cohort study. Sci Rep 2017;7:3679. 
88. Cai H, Shu XO, Xiang YB, Yang G, Li H, Ji BT, et al. Sleep duration and mortality: a prospective study of 113138 middle-aged and elderly Chinese men and women. Sleep 2015;38:529-36.

89. Pan A, De Silva DA, Yuan JM, Koh WP. Sleep duration and risk of stroke mortality among Chinese adults: Singapore Chinese health study. Stroke 2014;45:1620-5.

90. Grandner M, Mullington JM, Hashmi SD, Redeker NS, Watson NF, Morgenthaler TI. Sleep Duration and hypertension: analysis of $>700,000$ adults by age and sex. J Clin Sleep Med 2018;14:1031-9.

91. Noh W, Moon H. Short sleep duration as a risk factor of cardiovascular disease in Korean adults: Secondary Analysis of the Fifth Korean National Health and Nutrition Examination Survey. Iran J Public Health 2019;48:1239-47.

92. Itani O, Kaneita Y, Tokiya M, Jike M, Murata A, Nakagome S, et al. Short sleep duration, shift work, and actual days taken off work are predictive life-style risk factors for new-onset metabolic syndrome: a seven-year cohort study of 40,000 male workers. Sleep Med 2017;39: 87-94.

93. Choi JK, Kim MY, Kim JK, Park JK, Oh SS, Koh SB, et al. Association between short sleep duration and high incidence of metabolic syndrome in midlife women. Tohoku J Exp Med 2011;225:187-93.

94. Domínguez F, Fuster V, Fernández-Alvira JM, Fernández-Friera L, López-Melgar B, Blanco-Rojo R, et al. Association of sleep duration and quality with subclinical atherosclerosis. J Am Coll Cardiol 2019;73: 134-44.

95. Weil BR, Mestek ML, Westby CM, Van Guilder GP, Greiner JJ, Stauffer $\mathrm{BL}$, et al. Short sleep duration is associated with enhanced endothelin-1 vasoconstrictor tone. Can J Physiol Pharmacol 2010;88:777-81.

96. Cappuccio FP, Cooper D, D’Elia L, Strazzullo P, Miller MA. Sleep duration predicts cardiovascular outcomes: a systematic review and meta-analysis of prospective studies. Eur Heart J 2011;32:1484-92.

97. Logan JG, Kang H, Lobo JM, Sohn MW, Lin GM, Lima JAC, et al. Actigraphy-based sleep characteristics and aortic stiffness: the MultiEthnic Study of Atherosclerosis. J Am Soc Hypertens 2018;12:841-9.

98. Kwok CS, Kontopantelis E, Kuligowski G, Gray M, Muhyaldeen A, Gale CP, et al. Self-reported sleep duration and quality and cardiovascular disease and mortality: a dose-response meta-analysis. J Am Heart Assoc 2018;7:e008552.

99. Landry GJ, Best JR, Liu-Ambrose T. Measuring sleep quality in older adults: a comparison using subjective and objective methods. Front Aging Neurosci 2015;7:166.

100. Ohayon M, Wickwire EM, Hirshkowitz M, Albert SM, Avidan A, Daly FJ, et al. National Sleep Foundation's sleep quality recommendations: first report. Sleep Health 2017;3:6-19.
101. Kim EJ, Park CG, Park JS, Suh SY, Choi CU, Kim JW, et al. Relationship between blood pressure parameters and pulse wave velocity in normotensive and hypertensive subjects: invasive study. J Hum Hypertens 2007;21:141-8

102. Lutsey PL, McClelland RL, Duprez D, Shea S, Shahar E, Nagayoshi M, et al. Objectively measured sleep characteristics and prevalence of coronary artery calcification: the Multi-Ethnic Study of Atherosclerosis Sleep study. Thorax 2015;70:880-7.

103. Garfield V, Joshi R, Garcia-Hernandez J, Tillin T, Chaturvedi N. The relationship between sleep quality and all-cause, CVD and cancer mortality: the Southall and Brent REvisited study (SABRE). Sleep Med 2019;60:230-5.

104. He Q, Zhang P, Li G, Dai H, Shi J. The association between insomnia symptoms and risk of cardio-cerebral vascular events: a meta-analysis of prospective cohort studies. Eur J Prev Cardiol 2017;24:1071-82.

105. Cooper DC, Ziegler MG, Milic MS, Ancoli-Israel S, Mills PJ, Loredo JS, et al. Endothelial function and sleep: associations of flow-mediated dilation with perceived sleep quality and rapid eye movement (REM) sleep. J Sleep Res 2014;23:84-93.

106. Chair SY, Wang Q, Cheng HY, Lo SW, Li XM, Wong EM, et al. Relationship between sleep quality and cardiovascular disease risk in Chinese post-menopausal women. BMC Womens Health 2017;17:79.

107. Hoevenaar-Blom MP, Spijkerman AM, Kromhout D, van den Berg JF, Verschuren WM. Sleep duration and sleep quality in relation to 12year cardiovascular disease incidence: the MORGEN study. Sleep 2011; 34:1487-92.

108. Wang ID, Chien WC, Chung CH, Tsai PY, Chang SY, Meng FC, et al. Non-apnea sleep disorder associates with increased risk of incident heart failure-a nationwide population-based cohort study. PLoS One 2019;14:e0209673.

109. Wu MP, Lin HJ, Weng SF, Ho CH, Wang JJ, Hsu YW. Insomnia subtypes and the subsequent risks of stroke: report from a nationally representative cohort. Stroke 2014;45:1349-54.

110. Slopen N, Williams DR. Discrimination, other psychosocial stressors, and self-reported sleep duration and difficulties. Sleep 2014;37:147-56.

111. Pimple P, Lima BB, Hammadah M, Wilmot K, Ramadan R, Levantsevych $\mathrm{O}$, et al. Psychological distress and subsequent cardiovascular events in individuals with coronary artery disease. J Am Heart Assoc 2019;8:e011866.

112. Batool-Anwar S, Goodwin JL, Kushida CA, Walsh JA, Simon RD, Nichols DA, et al. Impact of continuous positive airway pressure (CPAP) on quality of life in patients with obstructive sleep apnea (OSA). J Sleep Res 2016;25:731-8. 